\title{
SOME EXPERIMENTS IN LEARNING AND RETENTION.
}

\author{
By MAY SMITH AND Wm. McDOUGALL.
}

(From the Psychological Laboratory, Oxford.)

I. Bergson's distinction between habit and memory.

II. Description of the tests.

III. Conditions of Experiment.

IV. Method of working out the results.

V. Results.

VI. The part played by conation in learning.

$V I I$. Is there any improvement in retentiveness?

VIII. Conclusions.

\section{Bergson's distinction between Habit and Memory.}

THE following experiments represent an attempt to obtain by the method of experiment direct evidence of the influence of conation in some of the learning processes and to show in those processes its relation to mechanically determined associations. The investigation started from the contention of Professor Bergson that the word 'memory' is too frequently used as equivalent to the power of forming mechanical associations, whereas such a use overlooks those recollections which in their very nature are unique experiences, but which are not the less effectively reproduced. "The past survives under two distinct forms: first in motor mechanisms, secondly in independent recollections.... The memory of a lesson remembered in the sense of learnt by heart has all the marks of a habit...; the memory of each successive reading has none of the marks of a habit....It may be urged that these two recollections, that of the reading and that of the lesson, differ only as the less from the more and that...the lesson learnt is but a composite image in which all the readings are blended.... But it is no less certain that each of them considered as a new reading and not as a lesson better known is entirely sufficient to itself.... Of these two memories one is memory pure, the other is habit interpreted by memory ${ }^{1}$."

In most of the experiments undertaken to study problems of memory there has been an almost exclusive attention to those forms of retention

1 Bergson, Matière et Mémoire, Ch. $\mathrm{n}$. 


\section{Some Experiments in Learning and Retention}

which are described by Professor Bergson as being of the nature of habit, i.e. they have depended on the formation of associations by frequent repetition and have then been interpreted as holding true of all retention ${ }^{1}$. In actual experience it is not possible to fulfil all Professor Bergson's theoretical conditions, as the two factors called by him 'habit' and 'pure memory' co-operate in any given concrete case; but it is possible experimentally to bring about experiences which approximate to one rather than to the other. If all memory is of the habit type, then all tests which involve to any extent retention ought to correlate with those in which motor habit plays an obvious part, or at least they should correlate as highly with such as with others. If on the other hand Professor Bergson's distinction is fundamental, then we should expect the tests concerned with retention to fall into two groups; those of the habit type should correlate together and those predominantly involving pure memory should correlate together; but success in the one group would not necessarily carry along with it success in the other, e.g. we might find that people markedly good at tasks of the one type are weak at those of the other.

The tests chosen were intended to illustrate both modes of retention, i.e. reproduction of unique experiences and reproduction after repetition.

\section{Description of the Tests.}

The Blot Test. Ten cards on each of which was a large ink blot of irregular shape were shown to the subject in succession for 5 seconds each. These cards were then shuffled with 10 more of a like character which the subject had not seen. The 20 cards were then shown to the subject successively, at the rate of one card per two seconds, who was asked to say 'yes' or 'no' according as he had or had not seen the card before. Errors were of two kinds, viz. cards falsely recognised as having been seen, and cards unrecognised which had been seen. In working out the results the two kinds of error were not kept separate.

The Picture Test. In this a simple picture was shown to the subject for 10 seconds, at the end of which time he was asked to write a sufficiently detailed account of the picture to enable any person, with the requisite executive ability, after reading the written account to draw the picture. The pictures chosen had not previously been seen by the subjects. In selecting the pictures it was essential that they should be clear and unambiguous, without much detail and with definite colours; and it was found advisable to avoid anything which might offer an arithmetical

1 See MeDougall, Body and Mind, Ch. Xxiv. 
challenge, e.g. rows of nails on a box, as some subjects tended to spend all their time counting.

Most of the errors were errors of omission. For marking purposes the picture was divided into a number of units, and one mark was awarded for each correct unit.

The Prose Test. A passage of prose was read through slowly once, after which the subject was asked to reproduce the substance in detail, aiming at the meaning rather than at verbal reproduction. For marking, the passage was treated as the picture ${ }^{1}$.

Learning of Nonsense Syllables. Lists consisting of ten nonsense syllables were used. The lists were clearly printed on a card and each syllable was presented through a hole in a sheet of cardboard of such a size as to exhibit one syllable only. The experimenter moved the card so as to present each syllable to the subject for one second, and the subject was instructed to read the syllables aloud as they appeared and to make an effort to learn them by heart. The number of repetitions required to learn the series was noted. The syllables were all constructed mechanically and pains taken to avoid those suggesting any meaning.

The Typewriter Test. The typewriter used was an old-fashioned "Hammond" with black keys resembling those of a piano. Three keys $(a, b$ and $c)$ were distinguished from the others by being painted a light colour. The subject was instructed to start at the middle key $(b)$, then to strike the marked key to the right $(c)$, then to strike the middle key $(b)$, then the one to the left $(a)$ and back to the middle key $(b)$, keeping the elbow rigidly extended ${ }^{2}$. The two keys $(a)$ and $(c)$ were not equidistant from the middle key $(b)$ which was the 'space key.' The result of these movements was to print two letters on the paper. After the letters had been printed five times, the subject was told to close her eyes and to continue the movements which, if correct, she was allowed to continue until the letters had been correctly printed five times. If, however, she made a mistake, she was told to open her eyes and to print the letters again five times and so on. The number of repetitions required before the movements could be repeated automatically, was taken as a measure of the facility of habit formation ${ }^{3}$.

1 Cf. Whipple, Manual of Mental and Physical Tests, 398.

2 It was found necessary to insist on this as otherwise some subjects changed their method during the test; by insisting on this rigidity greater uniformity was obtained and higher reliability coefficients.

3 This test was done first with the right hand and then with the left, but as there was great uniformity of place position in the results, the two have been taken together in working out the correlation. 


\section{Some Experiments in Learning and Retention}

\section{Conditions of Experiment.}

The subjects of these experiments were 41 women students and the experiments all took place at the same time every day, viz. between 1.30 and 3 p.m., each subject coming three days in succession and doing a complete set of the five tests each day. In all forty-one adults completed the sets.

\section{Method of Working out the Results.}

The method of correlation used was the Product Moment Formula applied to ranks ${ }^{1}$. To get the reliability coefficient (Rel. Coef.) Dr Spearman's suggestion ${ }^{2}$ was adopted, the results of the first and third day being amalgamated and their correlation with the second day's results worked out.

The probable error (in brackets) of the uncorrected coefficient was worked on the formula

$$
\frac{7063\left(1-r^{2}\right)}{\sqrt{ } n}
$$

V. Results.

\begin{tabular}{|c|c|c|c|c|c|c|c|c|}
\hline Blote ... & $\cdots$ & $\ldots$ & $\begin{array}{c}\text { Blots } \\
-\end{array}$ & $\begin{array}{c}\text { N.s. } \\
.05 \\
(\cdot 11)\end{array}$ & $\begin{array}{c}\text { Pict. } \\
.53 \\
(.07)\end{array}$ & $\begin{array}{l}\text { Pr. } \\
\cdot 26 \\
(\cdot 10)\end{array}$ & $\begin{array}{c}\mathrm{T} . \\
-\cdot 05 \\
(\cdot 11)\end{array}$ & $\begin{array}{c}\text { Rel. Coef. } \\
.50\end{array}$ \\
\hline Nonsense sy & llables & $\ldots$ & $\cdot 05$ & - & $\begin{array}{l}-03 \\
(\cdot 11)\end{array}$ & $\begin{array}{c}-48 \\
(\cdot 08)\end{array}$ & $\begin{array}{c}\cdot 61 \\
(.07)\end{array}$ & -68 \\
\hline Picture & $\ldots$ & $\ldots$ & .53 & $\begin{array}{c}.03 \\
(\cdot 11)\end{array}$ & - & $\begin{array}{l}.22 \\
(\cdot 10)\end{array}$ & $\begin{array}{c}-.11 \\
(\cdot 11)\end{array}$ & .69 \\
\hline Prose ... & $\ldots$ & $\ldots$ & $\cdot 26$ & $\begin{array}{l}.48 \\
(.08)\end{array}$ & $\begin{array}{l}\cdot 22 \\
(\cdot 10)\end{array}$ & - & $\begin{array}{c}.34 \\
(\cdot 09)\end{array}$ & $\cdot 65$ \\
\hline Typewriter & ... & $\cdots$ & -.05 & $\begin{array}{c}.61 \\
(.07)\end{array}$ & $\begin{array}{c}-\cdot 11 \\
(\cdot 11)\end{array}$ & $\begin{array}{c}.34 \\
(-09)\end{array}$ & - & $\cdot 65$ \\
\hline
\end{tabular}

The other results with a group of 12 children are:

Recognition test and 8 nonsense syllables $\cdot 03$ p.e. $\cdot 19$.

$$
" \quad " 10 \quad, \quad,-03, \cdot 19 .
$$

Of these tests the 'blots' and the 'picture' approximate to what Prof. Bergson calls 'pure memory,' inasmuch as each represents a specific experience unique in the history of the subject; there could be no question here of learning by repetition.

On the other hand, in the learning of the nonsense syllables and the fixing of the movements of the typewriter test there are all the characteristics of habit formation ${ }^{3}$.

1 W. Brown, Mental Measurement, 48-49.

2 This Journal, III. Pt. 3.

3 Bergøon, Matière et Mémoire, Ch. II. 
When we turn to the table of correlation we find that these two, the nonsense syllables and the typewriter, correlate together highly, viz. $\cdot 61$, while the two tests where the habit factor is at a minimum, viz. the 'blots' and 'picture,' correlate together to the extent of 53 ; but between each member of this latter group and either member of the other groups there is an absence of correlation, viz. .05 and - .05 respectively for the 'blots' with the nonsense syllables and the typewriter and $\cdot 03$ and $-\cdot 11$ for the 'picture' with the nonsense syllables and the typewriter. We thus seem to get two well-marked groups; $(a)$ those tests of what Prof. Bergson calls 'pure memory' dependent on the meaning of the whole, which, treated statistically, show high correlation; $(b)$ those tests showing all the characteristics of habit formation, which correlate with each other but not with either member of the other group.

Turning now to the 'reproduction of prose' test, we see that it shows an affinity with both groups, viz. :26 with the 'blots' and $\cdot 22$ with the 'picture,' and on the other hand $\cdot 48$ and $\cdot 34$ with the nonsense syllables and the typewriter test. In analysing the results there seems to be a considerable amount of literal reproduction: the passages chosen contained many well-known phrases, e.g. "a few years ago," which by the majority of subjects were reproduced verbatim, i.e. they represent verbal habits; and such reproductions amount to 39 per cent. of the total. The substance, however, as a whole was new to the subjects and so approximates to the non-mechanically determined type. This test is interesting as showing the interrelation of the two types in one experience.

One point of practical importance might well be considered here. To a degree greater than is generally recognised, learning at school resolves itself into the formation of mechanical associations between symbols, e.g. the association between the written and spoken symbol in reading, or between the corresponding symbol in another language, the learning by heart of tables, declensions, etc. All these must, for effective use, become mechanical by constant repetition. Now some children seem to find the making of such mechanical associations extremely difficult and hence will be handicapped in most of the subjects of a school curriculum (the exception will probably be scientific studies and handwork); such children may gain a quite undeserved reputation for stupidity ${ }^{1}$.

Again it is possible that some of the discrepant results obtained in

1 This will be particularly so when the curriculum gives a disproportionate amount of time to linguistic subjects; in such a case a child may learn to believe in its apparent stupidity and lose self-confidence. 


\section{Some Experiments in Learning and Retention}

the investigation of formal training may be due to ignoring this distinction: if the tests used depended mainly upon the power to form mechanical associations, a transference might be shown with this as a common factor.

\section{Vi. The part played by Conation in Learning.}

Mechanical association having been shown to be but one factor in retention, it remains to be investigated whether the success of the learning process is affected by reliance on this factor. That is to say, is learning more successful when conation or the will to learn is operative, or when the influence of quasi-mechanical repetition is allowed full sway? The material forming the subject matter of these experiments was nonsense syllables, chosen because a sequence of such syllables has, as a whole, no meaning (hence it is possible to avoid the complication of the uncertain and incalculable operation of varying interest), and also because an indefinite number of sequences of equal difficulty can be produced. For learning purposes the syllables were printed on strips of paper fastened round a cylindrical drum which could be wound up to revolve at a given speed. A piece of cardboard with a window cut in it, placed in front of the drum, permitted but one syllable at a time to be seen; the machine was arranged to show each syllable for one second. The learner noted each reading of the set and kept a record of the number of repetitions required before the sequence could be reproduced by heart.

The standard row for these experiments consisted of twelve syllables and the writers of this paper were the subjects except when a statement is made to the contrary. The experiments fall into two groups according to the attitude of the learner; in one group the learner makes an effort to learn the sequence of syllables as quickly as possible, while in the other he relies on learning them by mechanical repetition, maintaining an attitude of passivity towards them except in so far as each one is read aloud as it appears. This passive attitude required much practice on the part of both subjects before it could be successfully maintained, and subjectively it was a less interesting mental state. Even the most rigidly constructed set of nonsense syllables acquires some meaning if the mind is allowed full activity; e.g. the place positions of certain syllables are noted, or some syllables are more interesting and pleasing than others. The learning is a problem the satisfactory completion of which is important, so that the total experience, while not perhaps to be described as thrilling, is nevertheless interesting. But in learning the 
series passively, all this excitement was absent, and the whole experience seemed 'flat.' After some experience both subjects could adopt the passive altitude at will.

Averaging about 20 experiments of each type we find in the case of one subject that 13 repetitions are required to learn rows of nonsense syllables when making the maximum effort to do so, and in the case of the other subject that 9 repetitions are required. When however no effort is made and reliance is placed only on the formation of mechanical associations by repetition, an average of 89 repetitions is required for one subject and 100 for the other. That is, from seven to eleven times as many repetitions are required to learn the same number of syllables by heart.

Again, if in the case of passive learning we compare each subject's performance at the beginning with his performance after some months' practice, we find a gradual increase in the number of repetitions required to learn each row; in the case of one subject the increase is from 39 to 165 repetitions and in the case of the other from 45 to 204, an increase dependent upon the increasing success with which the passive attitude was maintained. In other words, the greater the passivity and therefore the greater the rôle of mechanical determination, the greater the number of repetitions required, i.e. the less successful the learning.

But it may be that, when the learning has once been effected by this great expenditure of time, the material learnt is retained more effectively than when learnt actively; and there may be some such advantage in mechanical or passive learning. Now the test of effective retention is the success with which the material learnt can be recalled, and for experimental purposes the measure of that success is the number of repetitions required to relearn the same material after the lapse of a given interval. A comparison can thus be made between the number of repetitions required to relearn actively a set of nonsense syllables which has been learnt actively and the number of repetitions required to relearn actively a group which originally was learnt passively. If as many repetitions are required to relearn a group after an interval as are required to learn it at first, then the original learning has for practical purposes been of no avail: if the original learning has been perfectly retained then no repetitions would be required to relearn, i.e. the sequence learnt could be recalled at will.

Turning now to these experiments we find that, averaging 20 attempts in the case of one subject, nine repetitions are required to learn a set of syllables when an efiort has been made and that four 


\section{Some Experiments in Learning and Retention}

repetitions are required to relearn after an interval of 24 hours; i.e. there is a gain of five repetitions representing the effectiveness of the retention. On the other hand, we find that when no effort has been made, an average of 99 repetitions for learning requires an average of five repetitions to relearn; i.e. the retention is not as effective as when the original learning has been done actively, although there were considerably more repetitions. Averaging 20 attempts in the case of the other subject, we find that 13 repetitions are required to learn the syllables actively and 90 to learn them passively, and that to relearn the same series after an interval of 24 hours takes eight and seven repetitions respectively; i.e. the passive learning does in this case require one less repetition for relearning than the active learning, but the difference is not proportional to the extra time taken.

Subjectively there was, with many of the series learned passively, a feeling of absolute unfamiliarity when relearning began; whereas on relearning after having learnt a list actively there was always a recognition that the series had been experienced before.

This however is after a short interval; it may possibly be that, when the time interval is longer, the frequent repetition involved in the passive learning may have the effect of preventing the decay of the material learnt. To test this some experiments were made to measure the influence of the time interval. The contrasting time intervals were, $(a)$ between 7 and 18 days for the long interval, $(b)$ under 24 hours for the short interval.

(a) The records of two subjects were obtained. In the case of one subject 10 repetitions were needed to learn several series actively, and 6 repetitions for relearning after a long interval: 40 repettitions were required for passive learning and 9 repetitions for relearning1. The other subject required an average of 8 repetitions for learning actively and $5 \cdot 6$ repetitions to relearn the same after a long interval; when learning passively he required an average of 172 repetitions for learning and 7.5 repetitions for relearning.

With both subjects after a long interval the loss is greater when the initial learning has been passive than when there has been the will to learn; so that there is little difference between the number of repetitions required for relearning what has once been learned passively and the number of repetitions required to learn for the first time; whereas when the original learning has been active there is clear proof of retention. The effects then of passive learning wear off much more quickly.

1 The figures state the averaged results. 
(b) When the time interval is short, i.e. less than 24 hours, we get the following results. One subject requires an average of 10 repetitions to learn a series actively, and an average of 6 repetitions to relearn, and an average of 41 repetitions to learn a similar series passively and 4 repetitions for relearning; here there seems to be some superiority in the passive learning. The other subject requires an average of 7.5 repetitions to learn several series actively and 4 repetitions to relearn; and an average of 90 repetitions to learn similar series passively, and 5 repetitions to relearn; in this case there is an advantage on the side of the active learning.

Judged then by the standard of effective retention and recall over both longer and shorter intervals, passive learning stands condemned. Consequently the effort to learn plays a very real part in the learning process, and to assume that learning consists either solely or chiefly in the formation of verbal habits ky mechanical association is to assign to the least important factor the dominant place. In only one case was there any superiority in the retentiveness after passive learning, and that was when the interval was short.

\section{Is THERE ANy Improvement IN RETENTIVENESS?}

All investigators of the learning processes have realised the somewhat irregular but general improvement which takes place if the same type of active learning is continued over some considerable period. This improvement, which may be due to improved concentration on the task, or to better realisation of the problem or of the means to attack it, is generally described as improvement of memory by practice ${ }^{1}$. Now it is easy to measure this improvement, as it is only necessary to compare the average of the repetitions required to learn several series of syllables at the beginning of an investigation, with the number required to learn the same number of series after some months of practice. But can we measure also whether with practice there is any improvement, not only in the power to learn but also in the power to retain? Improvement in retentiveness may conceivably prove to be a factor even in the improvement in learning; but if there be such an improvement it will show itself more purely in a measurement of retention. Evidence of it may be sought by comparing the repetitions required for

1 The most elaborate investigation of this kind is that of Prof. Meumann and his collaborators. It is claimed that these experiments show great improvement of memory through practice. But the method does not attempt to distinguish between improvement in application to the task and improvement in retentiveness and we do not know of any attempt to measure improvement of retentiveness previous to our own. 


\section{Some Experiments in Learning and Retention}

relearning at the beginning and at the end of a given period of practice. We shall have, of course, the improvement due to improved methods of learning as a factor common both to learning and relearning; and if any improvement of relearning is exactly proportional to the improvement in learning, we may legitimately conclude that the improvement in both cases is the expression of the improved methods of learning, rather than to the improvement in retention. But, if there be a disproportionate improvement in relearning, so that relatively there is greater improvement in the relearning than in the learning, we may conclude that that improvement is due to a factor peculiar to the relearning process, which factor an only be improvement in the power to retain ${ }^{1}$.

For these particular experiments six subjects' records are available. The period of practice for five subjects was six months, during which almost daily practice was given; and in the case of one subject the period was twelve months. The general method of procedure was as follows. On one day a group of syllables was learnt, and 24 hours afterwards that same group was relearnt, and so on. Below is a table of the results:

\begin{tabular}{|c|c|c|c|c|c|c|}
\hline Subjects & $\begin{array}{l}\text { Av. of } 8 \text { expts. } \\
\text { giving no. of } \\
\text { repetitions } \\
\text { for learning } \\
\text { at beginning }\end{array}$ & $\begin{array}{c}\text { Av. of } 8 \\
\text { expts. } \\
\text { giving no. } \\
\text { of repeti- } \\
\text { tions for } \\
\text { learning } \\
6 \text { months } \\
\text { after }\end{array}$ & Gain & $\begin{array}{l}\text { Av. no. } \\
\text { of repeti- } \\
\text { tions to } \\
\text { relearn at } \\
\text { leginning }\end{array}$ & $\begin{array}{c}\text { Av. no. of } \\
\text { repetitions } \\
\text { to relearn } \\
6 \text { months } \\
\text { after }\end{array}$ & Gain \\
\hline A. & 14 & 8 & $43 \%$ & 7 & 4 & $43 \%$ \\
\hline B. & 16 & $9 \cdot 6$ & 40 & $5 \cdot 6$ & 3 & 47 \\
\hline C & 8 & 7 & - & 3 & 3 & - \\
\hline D. & 9 & $5 \cdot 6$ & 38 & $2 \cdot 8$ & $1 \cdot 2$ & 57 \\
\hline E. & 13 & 11 & 15 & 9 & 6 & $33_{3}^{2}$ \\
\hline F.* & 12 & 8 & $33 \frac{1}{3}$ & 6 & 4 & $33_{3}^{1}$ \\
\hline
\end{tabular}

It will be seen that the subject $C$. improves very little in either task; this subject was particularly good at all learning by heart and habitually relied upon the power.

Subjects A. and F. appear to make a proportional improvement both in learning and relearning, but in B., D. and E. there is more than a proportional improvement in the relearning; the improvement in learning being represented by gains of 40 per cent., 38 per cent. and 15 per cent. respectively; whereas the improvement in the relearning is

1 It should be noted that no effort was made during the intervals to recall consciously the learnt syllables; any temptation there might be to do this rarely survives the first few experiences of learning nonsense syllables, and where the experiments extend over some years such extra repetitions can be ruled out. 
represented by gains of 47 per cent., 57 per cent. and $33 \frac{1}{3}$ per cent. It seems then as if in some persons at least, practice in memorising produces improvement not only in learning but also in the power to retain what has been learnt ${ }^{1}$.

\section{Conclusions.}

In this paper we have adduced experimental evidence in support of Prof. Bergson's distinction between habit and memory; we have illustrated the great importance of effort or volition in rendering repetition effective in memorising; we have made experiments which constitute, we believe, the first attempt to investigate the questionDoes practice in memorising produce improvement of retention as well as of the power to commit to memory?-and we have obtained results which seem to show that in some persons such improvement may be produced.

1 For a discussion of the more philosophical considerations see McDougall, Body and Mind, Chs. xxrrI and xxrv.

(Manuscript received 29 August, 1919.) 